\title{
The Value-Added and Linkage Effect Analysis of Taiwan's Agricultural Sector
}

\author{
Wen-Hung Huang1, Sheng Ming Hsu², Hsing-Chun Lin³, Kenneth Bicol Dy4, Ching-Cheng Chang1,4, \\ Shih-Hsun Hsu ${ }^{*}$
}

\author{
${ }^{1}$ Department of Agricultural Economics, National Taiwan University, Taiwan \\ ${ }^{2}$ Department of Applied Economics, National Chung Hsing University, Taiwan \\ ${ }^{3}$ Department of Applied Economics, National Chiayi University, Taiwan \\ ${ }^{4}$ Institute of Economics, Academia Sinica, Taiwan \\ Email: ^m577tony@gmail.com
}

How to cite this paper: Huang, W.-H., Hsu, S. M., Lin, H.-C., Dy, K. B., Chang, C.-C., \& Hsu, S.-H. (2022). The Value-Added and Linkage Effect Analysis of Taiwan's Agricultural Sector. Modern Economy, 13, 79-97. https://doi.org/10.4236/me.2022.131006

Received: December 2, 2021

Accepted: January 24, 2022

Published: January 27, 2022

Copyright (c) 2022 by author(s) and Scientific Research Publishing Inc. This work is licensed under the Creative Commons Attribution International License (CC BY 4.0).

http://creativecommons.org/licenses/by/4.0/

(c) (i) Open Access

\begin{abstract}
There is an increasing consensus in Taiwan that for agricultural development and policy planning the traditional production-based agriculture perspective should be replaced with a value chain perspective. Accordingly, when considering the value-added contribution of Taiwan's agricultural sector, its relationship with upstream, midstream and downstream sectors should be considered and estimated altogether. In this study, we use the demand-side input-output (IO) methodology to compute and analyze the value-added and linkage effects of Taiwan's agricultural sector. We found that if all the contribution along the value chain is considered, agriculture sector accounts for approximately between $10.56 \%$ and $11.85 \%$ of GDP, which is a sevenfold increase compared to contribution based on its mere production value (i.e., $1.65 \%-1.87 \%$ of GDP). This study recommends that future agricultural policy planning, in addition to focusing only on the primary production agriculture, should also include the distribution sector and food and beverage services sector, such as regulations for e-commerce sales channels for agricultural products, food hygiene regulations for the food and beverage industry, and cold chain logistics regulations for agricultural products.
\end{abstract}

\section{Keywords}

Production Agriculture, Food Value Chain, Value-Added, Linkage Effect, Input-Output (IO) Analysis, Gross Domestic Product (GDP)

\section{Introduction}

For the economists who specialized in economic development or agricultural 
economics, analyzing the role that agriculture should have in the development has been an important issue. Of major interest is the analysis of the relationships between agriculture and other economic sectors during the economic development, the use of resources (land, labor, capital) and the influence of institutional and technological factors in the long-run performance of agricultural sector. For this important issue, Pinilla and Willebald (2018) provide a general overview of the process of agricultural transformations and their interaction with the rest of the economy. In particular, Andersson and Till (2018) elaborate the most influential views of the role of agriculture in development theory, as well as explain the fluctuating scholarly attention to agriculture sector over time.

For the development of Taiwan's agriculture sector, Shih and Huang (2006) show that the rapid development and the structural transformation of Taiwan's economy have caused the relative position of agriculture in the total economy to decrease. According to the Directorate-General of Budget, Accounting and Statistics, Executive Yuan (DGBAS), agricultural production accounted for about $32 \%$ of GDP (gross domestic product) since 1952, but by 2003, this percentage had plummeted to $1.8 \%$. Although the contribution of agriculture to the overall economy has declined in terms of production, the non-economic function of agriculture is increasingly important, such as ensuring food security, providing green landscapes and promoting ecological balance. It is irreplaceable for other sectors, and the importance of agriculture cannot be measured solely by its production value only. With rapid urbanization and globalization, the traditional perspective on production agriculture may need to be extended into food supply (value) chain perspective.

In the 1990s, Imamura (1998) proposed the idea of "sixth industrialization (1 $\times 2 \times 3=6$ )", which combines agriculture, food processing, and retail to create new products or services by using agricultural products to increase their consumption and value-added, where primary agricultural production is the basis of the "sixth level". The sixth level of industrialization will not be effective if the economy only meets the needs of industrialization to the exclusion of primary agricultural producers.

Porter (1990), the pioneer of value chain analysis, believes that any industrial value chain is composed of a series of value activities, and the industrial value chain is a huge value system. The industrial value chain includes upstream suppliers-such as providers of raw materials, equipment and procurement services needed for the value chain-as well as the marketing channels and final consumers that complete the value chain activities downstream. Different industrial linkages form a value system, which encompasses supplier value chain, enterprise value chain, channel value chain, and consumer value chain. Competitive advantage can be strengthened whenever value is added to the raw material or intermediate product along this chain until it reaches the consumers.

$\mathrm{Hu}$ (2014) pointed out that although the three vital functions of agriculture (production, ecology and life) depend primarily on farmers, but the value of agricultural production is still determined by consumers. Thus, the quality, processing, 
packaging and marketing of agricultural products, which affect customer satisfaction, must be regarded as being crucial to the agricultural value chain; and should not, therefore, be set aside when discussing industrial development. Indeed, this multi-purpose value consideration of agriculture has become the international consensus in calculating agricultural output value. The agricultural sectors of many advanced agricultural countries truly reflect the importance of agriculture for the overall economy, and their GDP contribution comprises value-added from agricultural and agriculture-related industries in the upstream and downstream industries.

Taiwan's agriculture sector accounted for more than $2 \%$ of the total gross domestic product (GDP) before 2000, but with the change in Taiwan's industrial structure, it has fallen below $2 \%$ since 2001 (See Figure 1). Although the proportion of agricultural primary products in the overall economy has tumbled down over the years, one must bear in mind the dependence of industry and service sectors on the primary sector. This agricultural degringolade is an inevitable trend, yet this study argues and shows that the agricultural sector's direct and indirect contribution to the overall economic development is not as trivial as most policymakers might reckon.

Through value chain and input-output (IO) analysis, this study aims to reveal the enduring role of Taiwan's agriculture to GDP from a broader perspective, emphasizing its contribution through related industries along the value chain, including transformation and storage, processing and distribution, leisure and tourism. This moves beyond the narrow concept of agriculture as merely for production agriculture, which only contributes less than $2 \%$ to Taiwan's GDP since 2001.

\section{Literature Review}

The importance of Taiwan's agricultural sector has been generally assessed by the proportion of its value-added to the gross domestic product. Su (1980) emphasizes the position of a sector in the overall economic development should not

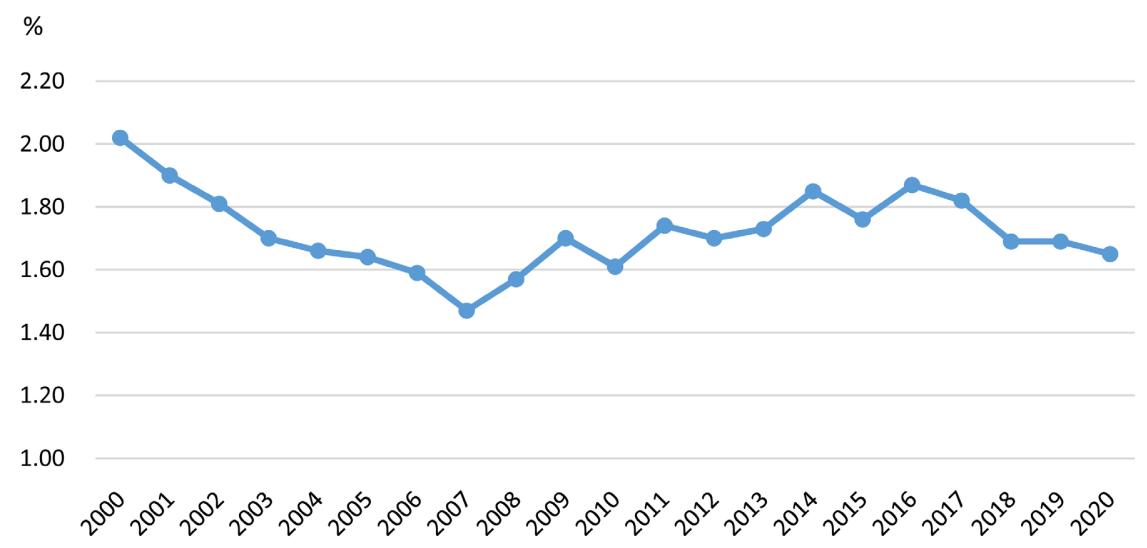

Figure 1. Taiwan's agricultural GDP share, 2000-2020. Source: The directorate general of budget, accounting and statistics of the executive yuan, Taiwan. 
only be judged by the output of the sector as a percentage of the GDP in the development process, because this only considers the direct impact of the sector's development on the overall economy, but in which the indirect impact of the sector's development on the overall economy is ignored. That is, both the direct and indirect impacts of the development of the sector on overall economic development should be measured in terms of the overall economy. Hsu (1999) analyzed the dynamic interaction between structural transformation and adjustment of the non-agricultural and agricultural sectors through a dynamic computable general equilibrium (CGE) model. He found that changes in final demand in the agricultural sector would also lead to changes in demand in the non-agricultural sector, for example, an increase in demand for horticultural crops would lead to an increase in demand in the horticultural materials industry. Yeh (2004) also used CGE and found that research and development in the agricultural sector contributed to the growth of non-agricultural sector. Therefore, when measuring the importance of the agricultural sector, its relevance to other sectors ought not to be neglected.

To measure the importance of agriculture, Xiao (1993) used Taiwan's input-output (IO) table data and Industry, Commercial, and Service census data to estimate the output value of food processing and transportation derived from the production of agricultural, livestock, and fishery products in Taiwan, and incorporated it into agricultural output value.

Lin, C.Y. (2005) also studied the relationship of agriculture with other sectors in Taiwan using IO analysis. The results show that the share of the transportation service sector is 2 to 3 times higher than that of primary agricultural products. Likewise, Edmondson (2002) used the inter-industry independence coefficient matrix and national income data to estimate the domestic and foreign consumers' demand for US agricultural products over the years and their contribution to the entire economic system. After having analyzed the correlation between primary agriculture and related industries, he found that transport services accounts for the largest share of the agricultural value along its whole value chain.

Lipton et al. (1998) estimated that the agricultural primary industry in the US in 1996 only accounted for less than 1\% of the GDP of the US. But after taking into account agriculture's connection with related industries-such as agricultural fertilizers, pesticides, feed, and agricultural machinery, and downstream food processing, freezing, transportation, warehousing, transportation and marketing, insurance, catering, and even leisure farms-it was found that the total contribution of agriculture and agriculture-related sectors to US GDP was as high as $13 \%$.

Chang et al. (2009) used the 2004 IO table in Taiwan to analyze the contribution of the agricultural sector to other related sectors. The results of the study showed that, after considering the indirect contribution of agriculture, its production value is $8.6 \%$ of the economy's total output value, while its value-added comprises $13.5 \%$ of GDP. If only direct contributions are considered, these ratios 
will only be $1.4 \%$ and $2.1 \%$, respectively. From these numbers, one cannot deny the role of primary industry in the development of other upstream and downstream agricultural enterprises.

A number of researchers have used econometric modelling to reveal the contribution of agriculture to overall national GDP. For example, Chongela (2015) used Mean Model to show that agriculture sector in Tanzania accounted for about $26 \%$ of its GDP, making it the highest contributor in their economy. They further decomposed the results by subsector: crops (18.93\%), livestock $(4.70 \%)$, and fisheries (2.25\%). In light of this, he recommended that agriculture policy in Tanzania should not neglect these sub-sectors.

Through co-integration analysis, Khan et al. (2020) tested the long-run relationship of the primary sector with the secondary and tertiary sectors, and overall GDP. They likewise found a statistically significant linkage between these sectors to agriculture. Therefore, the authors highlighted the importance of coordinating the general economic strategies and agricultural policies, notably in allotting national budget for agricultural research, transportation, education, and extension services. Bint Zaman et al. (2021) also tested for such long-run relationships in Pakistan using autoregressive distributed lag bounds test and error correction model. Their results showed that a one-percent increase in real agricultural value-added has a significant long-run contribution of $0.35 \%$ on real GDP per capita. Hence, agricultural policies will definitely have an undeniable impact on the future development of their country.

Studies in other sectors have also made the use of IO models for such analyses. Wang (1990) and Lin, Y.C. (2008) explore the effects of the public engineering sector in driving other industries. Gupta (2014) also used India's 1982-2007 IO table to analyze the relationship between the Indian automotive industry and other industries and found that the automotive industry has driven the development in related industries such as machinery, automation electronics, information, materials and chemical industries.

There are important relationships between production agriculture and other related sectors that cannot be ignored. The past literature lacked an empirical analysis of the overall contribution from the agricultural supply (or value) chain, which was mainly divided into upstream (production agriculture), midstream (processing), and downstream (transportation, distribution and services). In order to further explore Taiwan's agricultural sector's contribution, we will use the input-output methodology to calculate its direct and indirect effects on other sectors along the whole value chain. For example, the increase in demand from the food and beverage sector will drive the production of the agricultural sector, and the contribution to the agricultural value chain can be calculated through the matrix of inter-industry interdependence coefficients.

\section{Methodology and Database}

\subsection{Methodology}

In this study, we apply the Leontief input-output model of Miller and Blair 
(2009) to calculate the linkage effects of the agricultural value chain in Taiwan based on the agricultural value chain scope defined by Lin and Chang (2004). We also use the domestic IO tables $\left(Z^{D}\right)$ to estimate the economic effect of agricultural sector production in Taiwan. In which a time series of Taiwanese consumers' final demand for agricultural and related products in Taiwan is constructed using domestic IO tables for 2011 and 2016, as well as national income, imports, exports, and agricultural fixed capital formation from 2011 to 2019. The difference between purchaser's price and producer's price was then used to convert the purchaser-priced final demand to producer-priced final demand. Finally, the producer-priced final demand matrix was used to estimate the final demand for domestic products by sector using the final demand for domestic products ratio in 2011 and 2016 (i.e., 2011 to 2015 final demand using 2011 IO table; and 2016 to 2019 final demand using 2016 IO table). The final demand matrix for domestic products is then used to calculate the value-added of Taiwan agricultural, forestry, fishery and animal husbandry (AFFH) related products from 2011 to 2019. The basic formula for this calculation is:

$$
\mathrm{GDP}=v *\left(I-A^{D}\right) * d *(1-m) * C * Y_{N I}
$$

The GDP represents the value-added vector, which represents the value-added created by the production of the final demand for products related to AFFH in Taiwan; $V$ represents the value-added rate, which is the ratio between primary inputs and total output; the matrix $\left(I-A^{D}\right)$ represents the degree of industry linkage for domestic products; $d$ represents the proportion of domestic products in the final demand for each sector in the 2011 and 2016 IO tables; $m$ represents the difference between the purchasers' and producers' price; $C$ is the matrix of the percentage of total expenditures in each sector that are related to the agricultural sector; and finally, $Y_{N I}$ is a vector containing the historical expenditure amount of GDP by expenditure use in the National Income Statistics.

The inter-industry interdependence coefficients matrix is calculated through the matrix of sales distribution coefficient per unit of output product, considering the direct and indirect effect, and calculating the effect on the output of other related sectors. Since this study considers the value-added of agricultural and related sectors created by the final demand, the Leontief input-output model is used.

The Leontief input-output model can be expressed as follows:

$$
\begin{gathered}
X_{1}=\left(Z_{11}+Z_{12}+\cdots+Z_{1 n}\right)+F_{1} \\
X_{2}=\left(Z_{21}+Z_{22}+\cdots+Z_{2 n}\right)+F_{2} \\
\vdots \\
X_{n}=\left(Z_{n 1}+Z_{n 2}+\cdots+Z_{n n}\right)+F_{n}
\end{gathered}
$$

(total output $=$ intermediate demand + final demand).

Where $i=1, \cdots, n$ and $j=1, \cdots, n$ industries; $X_{i}$ represents the output of the $i$-th industry; and $Z_{i j}$ represents the amount of $X_{i}$ used as input in the $j$-th industry, $F_{i}$ represents the final demand for products of $i$-th industry in 
the economic system, including household sector consumption, private investment, government expenditure, net exports, etc. Equation (2) can be written in matrix form:

$$
X=Z+F
$$

where $X$ represents the total output vector; $Z$ represents the inter-industry trading matrix (also known as the intermediate input or intermediate demand matrix); and $F$ represents the final demand vector. Among them, the intermediate input and final demand (excluding the imported part) can be further subdivided into demand for domestic products $\left(Z_{D}, Y_{D}\right)$ and for imported products $\left(Z_{M}\right.$ $\left.Y_{M}\right)$, so (3) can be rewritten as follows:

$$
X=Z_{D}+Z_{M}+Y_{D}+Y_{M}-M
$$

Since $Z_{M}+Y_{M}=M$, the above formula can be further transformed to:

$$
X=Z_{D}+Y_{D}
$$

Under the assumption of the fixed coefficient of the IO model, the technical relationship between input and output is fixed, that is,

$$
a_{i j}=Z_{i j} / X_{j}
$$

or

$$
a_{i j}^{D}=Z_{i j}^{D} / X_{j}
$$

Technically, $a_{i j}$ is called "direct input coefficient" or "technical coefficient"; $a_{i j}^{D}$ is called "domestic direct input coefficient".

The following equations in matrix can be obtained from Equations (6) and (7):

$$
Z=A X
$$

or

$$
Z^{D}=A^{D} X
$$

where $A$ represents an input coefficient matrix or a technical coefficient matrix whose elements are $a_{i j} ; A^{D}$ represents a national product input coefficient matrix whose elements are $a_{i j}^{D}$. Substituting (8) and (9) into Equations (3) and (5), respectively:

$$
(I-A) X=F
$$

or

$$
\left(I-A^{D}\right) X=Y^{D}
$$

$(I-A)$ is called the Leontief Matrix; $\left(I-A^{D}\right)$ is called the domestic Leontief matrix. When it is a nonsingular matrix, the solution $X$ can be solved as follows:

$$
X=(I-A)^{-1} F
$$

or

$$
X=\left(I-A^{D}\right)^{-1} Y^{D}
$$


$(I-A)^{-1}$ is the Direct plus Indirect Requirements Matrix, also known as the Inter-industry Interdependence Coefficients Matrix or the Leontief Inverse Matrix; and $\left(I-A^{D}\right)^{-1}$ is a matrix of domestic inter-industry interdependence coefficients.

Let $B=(I-A)^{-1}$, where $b_{i j}$ represents the elements in the matrix, which denote the amount that the $j$-th industry must purchase directly and indirectly from the $i$-th industry in order to meet the final demand for product $j$. Let $B^{D}=\left(I-A^{D}\right)^{-1}$, where $b_{i j}^{D}$ represents the element in the matrix, which denote the amount that the $j$-th industry must purchase directly and indirectly from the domestic $i$-th industry in order to meet the domestic final demand for product $j$.

\subsection{Scope Definition}

Because Taiwan area's agricultural structure is very similar to that of Japan, both being densely populated small island economies, following Lin and Chang (2004), the final demand for AFFH-related products follows the definition and scope of the Agriculture and Food System (AFS) of the Ministry of Agriculture, Forestry and Fisheries of Japan.

1) Primary industry: including agriculture, forestry, and fisheries.

2) Food industry: food manufacturing for the production of processed foods.

3) Materials supply industry: mainly feed, chemical fertilizers, organic fertilizers and pesticides.

4) Related investments: agricultural machinery, food processing machinery, fishing vessels, and food manufacturing related to the production of fixed capital, agricultural and forestry relations public utilities, fishing ports and other investments.

5) Catering: Mainly based on restaurants.

6) Related circulation industry: including commercial trading and transportation.

7) Leisure agriculture.

It mainly includes AFFH and processed food, and excludes other non-food processing sectors (such as textiles, leather, wood and bamboo products), because most of the raw materials in these non-food sectors come from imports. Since DGBAS publishes IO tables every five years, to measure the final demand for AFS output from 2011 to 2019, we used the growth rate of expenditures on each related product in the national income account as the basis for estimation. A table comparing the items in the national income expenditure account with those in the IO sector classification is provided in Appendix A1.

\subsection{Database and Estimation Procedures}

The components of final demand, such as private consumption, government consumption, fixed capital formation, inventory change, and exports, as revised according to the AFS definition, are described below.

1) Private consumption 
Since the AFS only includes AFFH and processed foods, unrelated sectors are excluded from the 2011 and 2016 IO tables. In recent years, with the development of food and agriculture education, many agricultural and fishery operators have transformed to engage in leisure agriculture and fishery operations. This has gradually produced indirect effects on the development of agriculture and fishery-related industries, and therefore included in the scope of AFS.

The catering related to leisure agriculture has been included under the catering service industry. Therefore, in order to avoid double counting, the calculation can only cover the expenditure on transportation and accommodation when the people are engaged in leisure activities in the leisure agriculture. Therefore, the agriculture-related consumption in the "catering service sector", "travel service sector", "accommodation service sector", and "transportation sector" were included in the calculation as follows:

a) Catering service sector

According to the private consumption amount in the 2011 and 2016 IO tables from DGBAS, the final demand of this sector was NTD 487.862 billion and NTD 711.131 billion. In other years, the private consumption of the catering service sector is estimated based on the annual growth rate of national food consumption over the years based on data from DGBAS.

b) Travel service sector

Based on the 2011 and 2016 IO tables from DGBAS, final demand for the whole travel service sector amounted to NTD 23.53 billion and NTD 37.58 billion, respectively. A survey of the COA reveals that the proportion of Taiwanese people who travelled to participate in leisure agricultural tourism was about $24 \%$ in 2006. This percentage if used to estimate the consumption of leisure agricultural tourism in Taiwan in 2011 and 2016, i.e., NTD 5.65 billion and NTD 9.01 billion for 2011 and 2016, respectively. Because IO tables are only published every five years. Remaining years are estimated based on the historical growth rate of the "Entertainment" category in the national income from the DGBAS.

c) Accommodation services sector

The accommodation service within leisure agriculture was calculated starting from a base figure on consumer spending on leisure agriculture calculated by Zheng (1992). Then, annual growth rates of the "Entertainment" category from the national income was used to calculate the 2011 and 2016 spending on leisure agriculture. Finally, it was multiplied by the proportion of accommodation expenses in the "2011 National Tourism Survey" and "2016 National Tourism Survey" (Tourism Bureau of the Ministry of Communications, 2012, 2017), which were estimated at $17.6 \%$ and $17.1 \%$, respectively. The consumer demand for accommodation in leisure agriculture for both years were computed as NT $\$ 4.86$ billion and NT\$7.12 billion, respectively.

d) Transportation sector

Among the transportation sectors, the transportation expenditure items belonging to the leisure agriculture include the petroleum refining sector, the rail vehicle transportation sector, and other land transportation sector. As in the case 
of the accommodation service sector, the 2011 and 2016 consumption expenditure on leisure agriculture were estimated using Zheng (1992) as base year and projected to 2011 and 2016 using annual growth rates from the "Entertainment" category in the national income. This was followed by multiplying the proportion of expenditure in the transportation sector in the "2011 National Tourism Survey" (Tourism Bureau of the Ministry of Communications, 2012, 2017) and the "2016 National Tourism Survey" by $25.4 \%$ and $24.4 \%$, respectively. The calculated transportation expenses for leisure agriculture amounted to NTD 7.96 billion and NTD 7.27 billion, respectively. This study assumes that half of the tourists who go to leisure farms and forest recreation areas drive by themselves, and the other half go by public transportation. The household demand for the transportation sector related to agriculture in 2011 and 2016 was calculated. Therefore, the expenditures for fuel costs (petroleum refining sector) in 2011 and 2016 are estimated to be approximately NTD 4.54 billion and NTD 4.68 billion, respectively. NTD 1.19 billion and NTD 0.81 billion were spent on railroads, and NTD 2.24 billion and NTD 1.78 billion were spent on roads in 2011 and 2016, respectively.

2) Government consumption

As "government consumption" is processed internally, government consumption for all sectors is listed in the Public Administration Service (Sector 157 in 2011 and Sector 155 in 2016). In order to calculate the final demand for each sector within the AFS, the correlation effect can be calculated through the domestic inter-industry interdependence coefficient matrix, therefore, the data of Public Administration service is taken as government spending.

3) Agricultural fixed capital formation

We calculate data on fixed capital formation in agriculture based on the COA data. The sectoral classifications under the IO table and COA data structure are mapped on Appendix A2.

4) Changes in inventory

Since agricultural products cannot be stored for long periods of time, there are no significant inventory changes. We calculated the relevant inventory changes based on the information from the COA and the Ministry of Economic Affairs. The two sectors with the highest production value among the primary products are paddy rice and hogs, so they were selected for this analysis. For the processed foods-the frozen food, dairy products, tobacco and wine sectors-changes in inventory are based on the actual industrial production statistics of the food processing industry. The following are the calculation methods and results for the major sectors.

a) Paddy rice:

In this study, reference is made to the "rice stocks" and annual average "rice price" in the Agricultural Statistics Report of the COA from 2011 to 2019 to obtain inventories and price data. See Table 1.

b) Hogs:

Data for the number of hogs raised were sourced from the Agricultural Statistics Annual Report of COA. Hogs are classified into three types depending on weight. In order to calculate the total weight at the end of the year, the average 
weights of per type were multiplied by the quantity of hogs per type. Since piglets are normally between 7 to $10 \mathrm{~kg}$, the average weight of each piglet is assumed to be $8.5 \mathrm{~kg}$. Hogs that are less than $30 \mathrm{~kg}$ are assumed to each weigh $15 \mathrm{~kg}$; and finally, average weight for hogs between 30 to $60 \mathrm{~kg}$ is assumed to be $45 \mathrm{~kg}$. Livestock price from the Agricultural Statistics Annual Report were used to obtain the dollar value of inventory and annual change thereof as shown in Table 2.

c) Frozen food, wine, dairy products, edible fats and oils:

This study uses the Ministry of Economic Affairs' "Industrial Production Statistics Annual Report" from 2011 to 2019 to estimate inventory changes for this industry. Using annual sales amount and sales volume for each item on Table 3,

Table 1. Changes in paddy rice inventory from 2011 to 2019.

\begin{tabular}{ccccc}
\hline Year & $\begin{array}{c}\text { Price } \\
\text { (NTD/ton) }\end{array}$ & $\begin{array}{c}\text { Stock } \\
\text { (tons })\end{array}$ & $\begin{array}{c}\text { Inventory amount } \\
\text { (NTD million) }\end{array}$ & $\begin{array}{c}\text { Change in inventory } \\
\text { (NTD million) }\end{array}$ \\
\hline 2011 & 21,603 & 614,376 & 13,272 & 3953 \\
2012 & 23,098 & 735,889 & 16,998 & 3726 \\
2013 & 22,174 & 907,256 & 20,118 & 3120 \\
2014 & 24,025 & 900,008 & 21,622 & 1505 \\
2015 & 23,079 & 790,812 & 18,251 & -3371 \\
2016 & 23,905 & 758,770 & 18,138 & -113 \\
2017 & 23,640 & 864,260 & 20,431 & 2292 \\
2018 & 21,980 & 988,561 & 21,728 & 1297 \\
2019 & 21,660 & $1,101,509$ & 23,858 & 2130 \\
\hline
\end{tabular}

Source: COA, the paddy rice inventory of agricultural statistics annual report 2019.

Table 2. Changes in inventory of Hogs from 2011 to 2019.

\begin{tabular}{cccccccc}
\hline Year & $\begin{array}{c}\text { Piglets } \\
\text { (quantity) }\end{array}$ & $\begin{array}{c}\text { Hogs } \\
(<30 \mathrm{~kg})\end{array}$ & $\begin{array}{c}\text { Hogs } \\
\text { (quantity) }\end{array}$ & $\begin{array}{c}\text { Weight } \\
\text { (quantity) }\end{array}$ & $\begin{array}{c}\text { or tons) } \\
\text { (quice }\end{array}$ & $\begin{array}{c}\text { Stock } \\
\text { (NTD }\end{array}$ & $\begin{array}{c}\text { Changes in } \\
\text { inventory }\end{array}$ \\
\hline 2011 & 907,023 & $1,596,821$ & $1,527,327$ & 100,392 & 71,980 & 7226 & 320 \\
2012 & 855,744 & $1,494,697$ & $1,488,286$ & 96,667 & 63,100 & 6100 & -1126 \\
million) & (ND million) \\
2013 & 808,322 & $1,432,041$ & $1,467,985$ & 94,411 & 64,510 & 6090 & -9 \\
2014 & 765,784 & $1,378,514$ & $1,407,385$ & 90,519 & 78,090 & 7069 & 978 \\
2015 & 754,453 & $1,345,728$ & $1,416,131$ & 90,325 & 71,440 & 6453 & -616 \\
2016 & 749,189 & $1,355,969$ & $1,369,837$ & 88,350 & 71,580 & 6324 & -129 \\
2017 & 752,138 & $1,373,532$ & $1,355,631$ & 88,000 & 77,200 & 6794 & 469 \\
2018 & 764,322 & $1,391,527$ & $1,337,819$ & 87,571 & 70,390 & 6164 & -629 \\
2019 & 768,129 & $1,418,864$ & $1,333,070$ & 87,800 & 71,810 & 6305 & 141 \\
\hline
\end{tabular}

Source: COA, the hog inventory of agricultural statistics annual report 2019. 
annual average unit prices could be estimated. These are then multiplied by year-end inventory of each item and summed to obtain the inventory of frozen foods. Finally, the value of inventory change was calculated. The results are shown in Table 3.

5) Customs output

This study collected export data on the relevant sectors under the AFS definition from the International Trade Center (ITC) trade map database.

However, it is important to take into account the industry classification adjustments in 2011 and 2016. Table 4 shows the comparison between the classification of agriculture and related industries in 2011 and 2016.

Table 3. Changes in inventory of frozen foods, alcohol, and dairy products from 2011 to 2019 (unit: NTD million).

\begin{tabular}{cccccccccc}
\hline Sector & 2011 & 2012 & 2013 & 2014 & 2015 & 2016 & 2017 & 2018 & 2019 \\
\hline Frozen foods & 456 & -482 & -579 & 334 & 595 & 393 & 64 & -229 & 493 \\
Fats & 911 & -265 & -238 & -472 & -82 & 63 & 138 & -376 & 17 \\
Alcohol & 494 & 178 & -545 & -42 & 530 & -645 & 1190 & 848 & -967 \\
Dairy products & -150 & -34 & 3 & -54 & 71 & 11 & -76 & 17 & 27 \\
\hline
\end{tabular}

Source: Ministry of economic affairs, the frozen foods, alcohol, and dairy products inventory of "industrial production statistics annual report" 2011-2019.

Table 4. Classification of agricultural and agriculture-related sectors in 2011 and 2016.

\begin{tabular}{|c|c|c|}
\hline Sector & 2011 (166 sectors) & 2016 (164 sectors) \\
\hline Agriculture & Sector $001-011$ & Sector $001-011$ \\
\hline \multicolumn{3}{|l|}{ Agricultural input } \\
\hline Mining industry & Sector $012-014$ & Sector $012-013$ \\
\hline Material manufacturing & Sector 031-109 & Sector $030-107$ \\
\hline Hydropower construction & Sector $110-120$ & Sector $108-118$ \\
\hline Financial Services & Sector $139-144$ & Sector $137-142$ \\
\hline Business advertising service & $\begin{array}{c}\text { Sector } 133-138 \\
145-166\end{array}$ & $\begin{array}{c}\text { Sector 131-136, } \\
143-164\end{array}$ \\
\hline \multicolumn{3}{|l|}{ Food processing industry } \\
\hline Food & Sector $015-027,029$ & Sector $014-026,029$ \\
\hline Tobacco and alcohol & Sector 028,030 & Sector 027,029 \\
\hline \multicolumn{3}{|l|}{ Transportation service industry } \\
\hline Transportation warehousing & Sector $124-130$ & Sector $122-128$ \\
\hline Wholesale and retail & Sector $121-123$ & Sector $119-121$ \\
\hline Food and Beverage service & Sector 132 & Sector 130 \\
\hline Accommodation service & Sector 131 & Sector 129 \\
\hline
\end{tabular}

Source: This study. 


\section{Empirical Results and Analysis}

First, the domestic final demand matrix defined by the AFS for 2011 to 2019 is multiplied by the domestic IO table $\left(I-A^{D}\right)^{-1}$ domestic inter-industry interdependence coefficients matrix for 2011 and 2016, respectively, to obtain the output created by Taiwan's agriculture and related industries. Afterward, this vector is multiplied by the value-added rate of the industry in the year to get the effect of AFS on the value added of agriculture and related industries.

By using the broad definition of AFS agriculture, the upstream and downstream related industries are taken into account, and both direct and indirect effects, which comprise the actual impact of agriculture on the overall economy, are fully captured. The results show that if we look at the agricultural production, the impact on the overall economy is about $1.8 \%$ only, and if we consider the upstream factor inputs driven by agriculture, such as pesticides and fertilizers, as well as the downstream food and beverage services, and wholesale and retail, it will reach about $11 \%$. The study also provides insight into the individual driving effects of agricultural production on the agricultural input industry, food processing industry, and transportation service industry.

Table 5 and Table 6 show that the value-added of Taiwan's agricultural value chain in 2011 to 2019 ranged from NTD 1542 billion to 2243 billion, accounting

Table 5. Contribution of Taiwan AFS to GDP using inter-industry interdependence coefficients matrix (value-added; in NTD million).

\begin{tabular}{|c|c|c|c|c|c|c|c|c|c|}
\hline Sector & 2011 & 2012 & 2013 & 2014 & 2015 & 2016 & 2017 & 2018 & 2019 \\
\hline Agriculture primary products & 245,783 & 242,400 & 255,728 & 289,642 & 282,034 & 327,502 & 328,835 & 312,562 & 318,543 \\
\hline Agricultural input & 188,928 & 196,850 & 203,246 & 210,284 & 216,480 & 268,597 & 274,048 & 290,629 & 298,653 \\
\hline Mining industry & 1389 & 1202 & 1229 & 1271 & 1265 & 993 & 1047 & 1159 & 1085 \\
\hline Material manufacturing & 32,479 & 34,157 & 34,974 & 36,568 & 36,948 & 38,248 & 39,936 & 42,744 & 43,660 \\
\hline Hydropower construction & 58,124 & 61,663 & 63,196 & 64,959 & 67,174 & 79,363 & 80,380 & 85,445 & 87,640 \\
\hline Financial Services & 30,626 & 29,530 & 31,359 & 32,041 & 32,780 & 49,451 & 50,947 & 54,261 & 54,788 \\
\hline Business advertising service & 61,695 & 65,424 & 67,429 & 70,135 & 72,789 & 100,542 & 101,737 & 107,020 & 111,480 \\
\hline Food processing industry & 203,975 & 212,958 & 216,432 & 220,449 & 230,099 & 260,966 & 269,454 & 296,954 & 310,576 \\
\hline Food & 108,480 & 117,028 & 120,842 & 125,551 & 131,077 & 152,046 & 155,943 & 165,149 & 175,408 \\
\hline Tobacco and alcohol & 95,495 & 95,930 & 95,590 & 94,898 & 99,022 & 108,920 & 113,511 & 131,805 & 135,168 \\
\hline Transportation service industry & 908,129 & 973,759 & 995,098 & $1,013,951$ & $1,067,560$ & $1,172,763$ & $1,167,968$ & $1,265,734$ & $1,315,925$ \\
\hline Transportation warehousing & 29,017 & 30,706 & 31,606 & 32,788 & 33,863 & 42,999 & 43,449 & 46,017 & 47,622 \\
\hline Wholesale and retail & 645,420 & 699,260 & 713,006 & 717,547 & 760,940 & 820,270 & 806,337 & 885,691 & 917,577 \\
\hline Food and Beverage service & 232,583 & 242,607 & 249,265 & 262,352 & 271,444 & 308,741 & 317,440 & 333,242 & 349,914 \\
\hline Accommodation service & 1108 & 1186 & 1221 & 1265 & 1313 & 752 & 742 & 784 & 812 \\
\hline total & $1,542,20$ & $1,621,093$ & $1,665,443$ & $1,729,01$ & $, 790,649$ & $2,029,828$ & $2,040,305$ & $2,165,88$ & $2,243,697$ \\
\hline
\end{tabular}

Source: Computed in this study. 
Table 6. Contribution of AFS to GDP using inter-industry interdependence coefficients matrix (percentage).

\begin{tabular}{ccccccccccc}
\hline Sector & 2011 & 2012 & 2013 & 2014 & 2015 & 2016 & 2017 & 2018 & 2019 \\
\hline Agriculture primary products & 1.72 & 1.65 & 1.68 & 1.80 & 1.68 & 1.87 & 1.83 & 1.70 & 1.68 \\
Agricultural input & 1.29 & 1.31 & 1.30 & 1.27 & 1.26 & 1.53 & 1.52 & 1.58 & 1.58 \\
Mining industry & 0.01 & 0.01 & 0.01 & 0.01 & 0.01 & 0.01 & 0.01 & 0.01 & 0.01 \\
Material manufacturing & 0.23 & 0.23 & 0.23 & 0.23 & 0.22 & 0.22 & 0.22 & 0.23 & 0.23 \\
Hydropower construction & 0.41 & 0.42 & 0.41 & 0.40 & 0.40 & 0.45 & 0.45 & 0.47 & 0.46 \\
Financial Services & 0.21 & 0.20 & 0.21 & 0.20 & 0.20 & 0.28 & 0.28 & 0.30 & 0.29 \\
Business advertising service & 0.43 & 0.45 & 0.44 & 0.44 & 0.43 & 0.57 & 0.57 & 0.58 & 0.59 \\
Food processing industry & 1.43 & 1.45 & 1.42 & 1.37 & 1.37 & 1.49 & 1.50 & 1.62 & 1.64 \\
Food & 0.76 & 0.80 & 0.79 & 0.78 & 0.78 & 0.87 & 0.87 & 0.90 & 0.93 \\
Tobacco and alcohol & 0.67 & 0.65 & 0.63 & 0.59 & 0.59 & 0.62 & 0.63 & 0.72 & 0.71 \\
Transportation service industry & 6.35 & 6.63 & 6.53 & 6.29 & 6.37 & 6.68 & 6.49 & 6.89 & 6.95 \\
Transportation warehousing & 0.20 & 0.21 & 0.21 & 0.20 & 0.20 & 0.24 & 0.24 & 0.25 & 0.25 \\
Wholesale and retail & 4.51 & 4.76 & 4.68 & 4.45 & 4.54 & 4.67 & 4.48 & 4.82 & 4.85 \\
Food and Beverage service & 1.63 & 1.65 & 1.64 & 1.63 & 1.62 & 1.76 & 1.77 & 1.81 & 1.85 \\
Accommodation service & 0.01 & 0.01 & 0.01 & 0.01 & 0.01 & 0.00 & 0.00 & 0.00 & 0.00 \\
total & 10.78 & 11.04 & 10.93 & 10.73 & 10.68 & 11.56 & 11.35 & 11.7911 .85 \\
\hline
\end{tabular}

Source: Computed in this study.

for $10.68 \%$ to $11.85 \%$ of Taiwan's GDP. Furthermore, the value-added created by AFS is divided into four categories: primary (unprocessed) products, agricultural inputs, food processing, and transportation service sector. The agricultural inputs are the related upstream industries, whereas the food processing and transportation service sector are the related downstream industries. This shows internal structure of agricultural value chain and its changes. The largest proportion is in the transportation services sector, which accounts for about $60 \%$ of the total AFS contribution to GDP in $2011(6.35 / 10.78=58.91 \%$; see Table 6); followed by the agricultural primary product sector, which accounts for about $16 \%$ $(6.35 / 10.78=15.96 \%)$ in 2011 ; and the food processing industry, which accounts for $13 \%$. The smallest contribution is made by the agricultural input industry with only about $12 \%$.

In the transportation service industry, the most influential sub-sector is wholesale and retail, which consistently reached about $5 \%$ throughout the period covered in the study. This indicates that the contribution of agriculture, in addition to the production of crops, livestock and fishery, also drives the value-added of the wholesale and retail sector. The food and beverage service sector was the next largest, at an average of $1.7 \%$ across the study period. Therefore, when con- 
sidering the contribution of agricultural sector, we should not only think from the perspective of production agriculture, but also from the perspective of the whole agricultural value chain.

\section{Concluding Remarks}

With rapid urbanization and globalization, the perspective of production agriculture has been extended to the perspective of food value chain. As a normal development trend, the GDP contribution of production agriculture is expected to decline due to trade liberalization and structural change. However, the GDP contribution of food value chain or agricultural sector from the value chain perspective may still be too important to be ignored. That is, when considering the value-added of Taiwan's agricultural sector, the contribution of upstream, midstream and downstream sectors should be added together to reflect how important the current agricultural sector is.

From a narrow production viewpoint, Taiwan's agriculture contributes about $1.8 \%$ to the overall economy; but from the broader agricultural value chain viewpoint, this study found that Taiwan's agriculture contributes about $11 \%$ to the overall economy. The difference is due to the inclusion of both direct and indirect impacts of agriculture on its upstream and downstream related industries. This approach will provide a clearer understanding of which industries are driven by agriculture's contribution through linkage effects. When formulating agricultural policies in the future, apart from the traditional production side, complementary policies in other industry chains must also be considered.

And based on the decomposition of the contribution of the agricultural value chain to GDP, we find that the transportation service sector has the highest share of over $6 \%$. Within this sector, the subsector with the highest contribution is the wholesale and retail sector, followed by the food and beverage services sector. Hence, this study recommends that future agricultural policy planning, in addition to focusing on the primary agricultural production sector, should also do a more complete planning, which includes the sales channel and food and beverage services sector, such as regulations for e-commerce sales channels for agricultural products, food hygiene regulations for the food and beverage industry, and cold chain logistics regulations for agricultural products. This will be more beneficial to Taiwan's future agricultural development and overall economic prospects.

\section{Acknowledgements}

This research is supported by the Center for Sustainability Science, Academia Sinica of Taiwan under the Project No. AS-SS-107-02.

\section{Conflicts of Interest}

The authors declare no conflicts of interest regarding the publication of this paper. 


\section{References}

Andersson, M., \& Till, E. R. (2018). Between the Engine and the Fifth Wheel: An Analytical Survey of the Shifting Roles of Agriculture in Development Theory. In V. Pinilla, \& H. Willebald (Eds.), Agricultural Development in the World Periphery: A Global Economic History Approach (pp. 28-61). Palgrave Macmillan. https://doi.org/10.1007/978-3-319-66020-2_2

Bint Zaman, S., Ishaq, M., \& Niazi, M. A. (2021). Contribution of Agriculture Sector in Economic Growth of Pakistan: An Empirical Analysis. Journal of Applied Economics and Business Studies, 5, 103-120. https://doi.org/10.34260/jaebs.527

Chang, C. L., Chen, S. W., Peng, K. C., \& Yang, J. P. (2009). The Analysis of Inter-Industry Relations on Agribusiness in Taiwan. Chinese Journal of Agribusiness Management, 14, $1-23$.

Chongela, J. (2015). Contribution of Agriculture Sector to the Tanzanian Economy. American Journal of Research Communication, 3, 57-70.

Edmondson, W. P. M. (2002). Food and Fiber System Employment and Value Added: Food and Fiber System Important Part of Economy. Rural America, 17, 42-44.

Gupta, S. (2014). Automobile Clusters in India: A Comparative Analysis of Structure and Linkages (1982-2007). Unpublished Doctoral Dissertation, Jawaharlal Nehru University.

Hsu, S. H. (1999). A Dynamic CGE Analysis of Structural Adaptation in Taiwan's Agricultural Sector. National Science Council of the Executive Yuan.

Hu, X. H. (2014). Beyond Self-Innovative Value-Meeting the Era of "Value Agriculture". Taiwan Agricultural Policy and Farming, 259, 24-28.

Imamura, N. (1998). Sixth Industrialization for Aquaculture to Create Additional Values. 21 Seiki Murazukurijyuku, 1-28.

Khan, W., Jamshed, M., \& Fatima, S. (2020). Contribution of Agriculture in Economic Growth: A Case Study of West Bengal (India). Journal of Public Affairs, 20, e2031. https://doi.org/10.1002/pa.2031

Lin, C. Y. (2005). The Contribution of Taiwan's Agriculture to the Total Economy and Industry Linkage Analysis. Unpublished Master's Thesis, National Taiwan University, Department of Agricultural Economics.

Lin, H. C., \& Chang, C. C. (2004). Agricultural Value Added and Input-Output Analysis in Taiwan. Taiwan Agricultural Economics Series, 10, 1-24.

Lin, Y. C. (2008). The Inter-Industrial Linkage of the Transport Sector in Taiwan's National Economy: An Input-Output Approach. Unpublished Master's Thesis, Kainan University.

Lipton, K. L., Edmondson, W., \& Manchester, A. (1998). The Food and Fiber System: Contributing to the US and World Economies. Agricultural Information Bulletin No. 742, US Department of Agriculture, Economic Research Service. https://www.ers.usda.gov/publications/pub-details/?pubid=42158

Miller, R. E., \& Blair, P. D. (2009). Input-Output Analysis: Foundations and Extensions (2nd ed.). Cambridge University Press. https://doi.org/10.1017/CBO9780511626982

Pinilla, V., \& Willebald, H. (2018). Agricultural Development in the World Periphery. Palgrave Studies in Economic History, Palgrave Macmillan. https://doi.org/10.1007/978-3-319-66020-2

Porter, M. E. (1990). The Competitive Advantage of Nations. Harvard Business Review, 68, 73-93. https://doi.org/10.1007/978-1-349-11336-1 
Shih, M. L., \& Huang, B. W. (2006). A Study on Changes of Agricultural Structure and Agricultural Development in Taiwan. Journal of the Agricultural Association of China, 7, 324-342.

Su, M. J. (1980). Chain Analysis of the Agricultural Sector and Other Sectors in Taiwan. Unpublished Doctoral Dissertation, National Taiwan University, Department of Agricultural Economics.

Tourism Bureau of the Ministry of Communications (2012). 2011 National Tourism Survey. Ministry of Transportation and Communications, Executive Yuan.

Tourism Bureau of the Ministry of Communications (2017). 2016 National Tourism Survey. Ministry of Transportation and communications, Executive Yuan.

Wang, T. F. (1990). Analysis of the Economic Effects of Transportation and Communication Construction in Taiwan. Taipei Economic Inquiry, 30, 79-125.

Xiao, C. F. (1993). Taiwan's Agricultural Production and Its Derived Food Processing, Transportation and Production Value Estimation. Taiwan Agricultural Policy and Farming, 16, 24-28.

Yeh, C. Y. (2004). Study on the Impact of Research and Development Investment on Agricultural Competitiveness. Taiwan Agricultural Finance, 51, 191-230.

Zheng, H. Y. (1992). Evaluation of the Economic Contribution of Leisure Agriculture to Farmers' Income and National Tourism. Council of Agriculture, Executive Yuan. 


\section{Appendix A1. Sectoral Comparison between National Income Account and Input-Output Table}

\begin{tabular}{cl}
\hline Name of National Income account & \multicolumn{1}{c}{ Name of related sectors of input-output table } \\
\hline \multirow{2}{*}{ Food } & Cereals, Special Crop, Vegetable, Fruit, Misc. \\
& Horticulture Crop, Misc. Livestock, Forestry, \\
& Fisheries, Slaughter, Fats, Dairy, Rice, Flour, \\
& Animal Feed, Candy and baked Product, \\
& Sugar, Seasonings, Misc. Food, Catering service \\
Beverage & Non-Alcohol, Alcohol \\
Cigarette & Tobacco \\
& Petroleum refining, Accommodation service, \\
& Rail Vehicle transportation, \\
Entertainment & Other land transportation, Travel Service \\
&
\end{tabular}

Source: the Directorate General of Budget, Accounting and Statistics of the Executive Yuan, Taiwan, 2011 and 2016 Taiwan IO Table.

\section{Appendix A2. Estimation of Agricultural Fixed Capital Formation for Related Sectors in Input-Output Table}

\begin{tabular}{cl}
\hline Name of sector & Agriculture Fixed Capital Formation in Taiwan from COA \\
\hline Misc. & Based on the historical growth rate of capital formation for \\
land improvement and orchard development in the national \\
income statistics. \\
It is estimated based on the amount of breeding stock and \\
dairy cattle in the national income statistics, and the \\
proportion of hogs to the fixed capital formation of all \\
livestock in the input-output table in 2011 and 2016. \\
It is estimated based on the amount of breeding stock and \\
dairy cattle in the national income statistics, and the proportion \\
of misc. livestock to the fixed capital formation of all livestock \\
in the input-output table in 2011 and 2016. \\
It is estimated based on the historical growth rate of capital \\
formation and afforestation by the Agricultural Commission. \\
1) Agricultural and livestock industry machinery and equipment \\
2) Forestry logging machinery and equipment \\
3) Forestry other machines and equipment \\
4) Other machines and equipment for fishing \\
5) Agricultural products, marketing and other agricultural \\
products processing and storage machinery and equipment \\
1) Farming and transportation vehicles \\
2) Forestry transportation vehicles \\
3) Fishery land transportation vehicles \\
4) Agricultural transportation and transportation vehicles \\
1) Fishing vessel construction and repair transport equipment \\
2) Fishing boat mechanized operation equipment \\
\hline Machinery
\end{tabular}




\section{Continued}

1) Non-residential housing for agriculture and livestock
2) Farm and livestock farm equipment
3) Agricultural products, rice and fertilizer warehouse
4) Agricultural product distribution and sales yard expansion
and consignment equipment
Residence Build $\quad$ 5) Agricultural fruit and vegetable wholesale market and
equipment
6) Agricultural meat wholesale market and equipment
7) Agricultural fish wholesale market and equipment
8) Slaughterhouse and its equipment
1) Flood control irrigation
2) Farmland cultivation and improvement
3) Construction and fish conservation
4) Construction of fishing port and onshore equipment
1) Forest Road Construction and Maintenance
Misc. Construction
2) Forest protection equipment
3) Forest amusement equipment

Source: the COA of the Executive Yuan, 2011; 2016 Classification of input-output tables in Taiwan. 